\title{
THE GENETICS OF THE COLOUR PHASES OF THE ARCTIC SKUA
}

\author{
P. O'DONALD and P. E. DAVIS \\ Department of Genetics, University of Cambridge, \\ and Fair Isle Bird Observatory
}

Received 20.xi.58

\section{INTRODUCTION}

The Arctic skua, Stercorarius parasiticus, is a colonial sea bird whose range extends from Scotland into the Arctic regions. It is of genetic interest due to the cline in colour phases which it shows. These phases appear to fall into three more or less well defined types-pale, intermediate and dark - with pale predominating in the North of the range and dark in the South. At the time, however, when a survey of this cline was made (Southern, 1943), intermediates were not recognised and it was not until Williamson's work on the breeding biology at Fair Isle (e.g. Williamson, 195 I) that the existence of this third class was recognised. At Fair Isle, the breeding adults are trapped and colour ringed ; and the chicks—normally two in a brood-are caught and classified just before flying.

\section{DESCRIPTION OF THE PHASES}

The characters by which the phases may be recognised differ, of course, in the adults and chicks ; and, indeed, it will later be seen that the classification of chicks does not appear to correspond exactly with that of the adults.

In the adults, the pale phase is sharply marked off from intermediate ; but all graduations appear to exist between intermediate and dark. Pale is characterised by a white neck and belly ; in some birds the whole of the front of the body from the head downwards is white; in others the white area on the neck is separated from that of the belly by a darker band. The back and wings of the bird are always dark. Occasionally a pale phase bird appears in which the white is replaced by a brownish white. This form has been called "dusky pale" at Fair Isle ; but it appears genetically identical to the other pales : the mating pale $\times$ dusky pale has always produced apparently normal pale phase chicks. Dark phases are distinguished by having head, neck and body of the same dark brown colour. The intermediates, however, show a wide range of variation: the most clearly marked individuals have white necks (the belly here always being dark), but there are others in which the "cheeks" are only slightly lighter than the rest of the body giving the head a "capped " appearance. These birds are called "dark-intermediates" at Fair Isle. But it is clear that all grades between intermediate and dark are present and the dividing line is arbitrary.

In the chicks the distinctions observed are less sharply marked between all phases than in the adults. Chicks which have been called pale show broad rufous tips to the feathers of the wings and back ; the belly feathers, especially those between the legs, are white, though they may be more or less tipped with brown. Intermediates generally have fewer and narrower tips to the feathers of the back and wings ; the belly feathers are white at the base but have a dark band of greater or 
lesser extent at the tip. Dark chicks normally have completely dark feathers on the wings and back and on the belly, but some feathers may have narrow rufous tips : in any case it is the absence of white at the base of the feather that is judged to be the criterion. In general the belly characters seem to be more constant than the wings and back; but there are naturally individuals in which classification into one or other form is arbitrary. It should be noted, however, that the classification of pale chicks appears to correspond with that of pale adults for pale $\times$ pale matings have always produced pale chicks. For the other matings, however, of thirteen chicks that have been recaptured as breeding adults, one was misclassified: a "darkintermediate" chick became a dark adult. It is also interesting that an adult that was classified as "dark-intermediate" in one year became "dark" in the next. Clearly there is a problem of manifestation here.

\section{THE BREEDING DATA}

The matings pale $\times$ pale, pale $\times$ intermediate, pale $\times$ dark, intermediate $\times$ intermediate, intermediate $\times$ dark and dark $\times$ dark have been observed at Fair Isle since I95I when Williamson first started the classification of intermediates. The colony has greatly increased in size, from twenty-five pairs in I95 I to sixty pairs in I958. Table I shows the results obtained.

TABLE 1

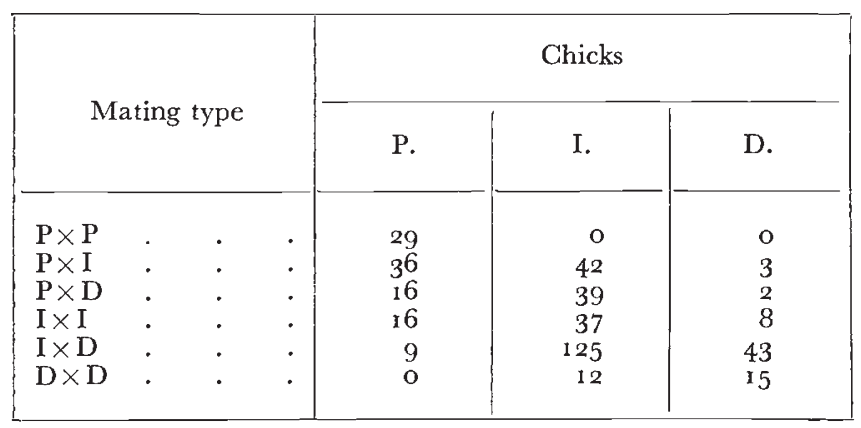

If it is assumed that two allelic genes are responsible for the existence of the three phases then clearly a certain proportion of the heterozygotes is liable to be misclassified as homozygous dark. It has already been mentioned that this is probable. It appears, however, that although the proportion of unrecognised heterozygotes among adults must be quite high, misclassification among the chicks can only occur in very slight degree. This is shown by the pale $\times$ intermediate matings where there can be no misclassification of adults : only three dark chicks have been produced. Similarly, among pale $x$ dark matings, there are only two dark chicks. It should further be noted that if misclassification of chicks were at all serious, then in intermediate $\times$ intermediate matings an excess of darks should be observed : in fact the number of darks is below expectation. It is quite possible, the boundary between dark and intermediate chicks being indistinct, that there is two-way misclassification. For these reasons, we shall consider that the few darks thrown by the pale $\times$ 
intermediate and pale $\times$ dark matings are really intermediates and shall add them to the number of intermediates.

Suppose a proportion " $\lambda$ " of the dark birds are really carrying the pale gene, i.e. they are heterozygous; if we call the pale gene " $p$ " and the dark gene " $\mathrm{P}$ ", then we have the following expectations for the three mating types (pale $\times$ dark, intermediate $\times$ dark and dark $\times$ dark) which supply information on " $\lambda$ ".

$\mathrm{A} \mathrm{P} \times \mathrm{D}$ mating will be $p p \times \mathrm{P} p$ with probability $\lambda$ and $p p \times \mathrm{PP}$ with probability $(\mathrm{I}-\lambda)$, thus an offspring is phenotypically $\mathrm{P}$ with probability $\lambda / 2$ and $\mathrm{I}$ with probability $\lambda / 2+(\mathrm{I}-\lambda)$, i.e. $\mathrm{I}-\lambda / 2$.

An $\mathrm{I} \times \mathrm{D}$ mating will be $\mathrm{P} p \times \mathrm{P} p$ with probability $\lambda$ and $\mathrm{P} p \times \mathrm{PP}$ with probability $(\mathrm{I}-\lambda)$ thus an offspring is phenotypically $\mathrm{P}, \mathrm{I}$ or $\mathrm{D}$ with respective probabilities $\lambda / 4, \lambda / 2+(\mathrm{I}-\lambda) / 2$, and $\lambda / 4+(\mathrm{I}-\lambda) / 2$, i.e. $\lambda / 4, \mathrm{I} / 2$ and $(2-\lambda) / 4$.

$\mathrm{A} \mathrm{D} \times \mathrm{D}$ mating is $\mathrm{P} p \times \mathrm{P} p, \mathrm{P} p \times \mathrm{PP}$ or $\mathrm{PP} \times \mathrm{PP}$ with respective probabilities $\lambda^{2}, 2 \lambda(\mathrm{I}-\lambda)$ and $(\mathrm{I}-\lambda)^{2}$ from which it results that an offspring is phenotypically $\mathrm{P}, \mathrm{I}$ or $\mathrm{D}$ with respective probabilities $\lambda^{2} / 4, \lambda(2-\lambda) / 2,(2-\lambda)^{2} / 4$.

TABLE 2

\begin{tabular}{|c|c|c|}
\hline Mating & Score, $\mathrm{S}$ & Information, I \\
\hline $\mathrm{P} \times \mathrm{D}$ & $-16 / \lambda+4 \mathbf{1} /(2-\lambda)$ & $57 / \lambda(2-\lambda)$ \\
\hline $\mathrm{I} \times \mathrm{D}$ & $-9 / \lambda+43 /(2-\lambda)$ & $177 / 2 \lambda(2-\lambda)$ \\
\hline $\mathrm{D} \times \mathrm{D}$ & $-12 / \lambda+4^{2} /(2-\lambda)$ & $27+27(2-\lambda) / 2 \lambda+27 \lambda / 2(2-\lambda)$ \\
\hline
\end{tabular}

Setting up the logarithmic likelihood expressions and differentiating with respect to $\lambda$ we get the following formulæ shown in table 2 for the score $S$ and information $I$ of each of the three mating types $P \times D$, $\mathrm{I} \times \mathrm{D}$ and $\mathrm{D} \times \mathrm{D}$. By equating the sum of the scores to zero we obtain the estimate of $\lambda$ based on the combined data. This is $0 \cdot 453988$.

The test of heterogeneity of the mating types in respect of the estimates of $\lambda$ to which they separately lead is based on $\mathrm{S}^{2} / \mathrm{I}$ (calculated for the value $0 \cdot 453988$ taken for $\lambda$ ), which is distributed as $\chi_{2}^{2}$ (chisquared for two degrees of freedom). This value comes out as $\mathrm{I} \cdot 4502$ (i.e. Probability 0.49 ). The agreement is clearly very good.

On this hypothesis we further expect the following ratios : $\mathbf{P} \times \mathbf{I}$ should give $\mathrm{P}: \mathrm{I}:: \mathrm{I}: \mathrm{I} ; \mathrm{I} \times \mathrm{I}$ should give $\mathrm{P}: \mathrm{I}: \mathrm{D}:: \mathrm{I}: 2: \mathrm{I}$; and $\mathrm{I} \times \mathrm{D}$ should give $\mathrm{I}: \mathrm{P}+\mathrm{D}:: \mathrm{I}: \mathrm{I}$.

We have shown in table 3 the observed segregations and $\chi^{2}$ for testing goodness of fit. Clearly the last figures contradict the I : I hypothesis. There are several reasons that could be put forward for this. The most simple assumes a viability disturbance : a deficiency of dark birds. An attempt at fitting, however, led to a very much reduced value for " $\lambda$ " and this value did not then fit the pale $\times$ dark data. There remain two possibilities : inheritance of the phases may 
depend on more than one locus; or the effect may be due in some way to the mode of collecting the data. To test an hypothesis based on the assumption that two loci are involved would necessitate the fitting of two more parameters concerned with the frequencies of the alleles at each locus; the further assumption would have to be made that union of gametes is at random. A simple dosage relation might be postulated : " $a a b b$ " as pale, " $a A b b$ " and " $a a b B$ " as intermediate and the rest as dark. Even so, in the intermediate $\times$ dark matings it would still appear that an excess of darks should be shown, whatever the frequencies of "A" and " B". The other possibility-of a bias in the classification of the chicks--would be very difficult to detect : this contingency is, however, indicated in the record books at Fair Isle where occasionally surprise is shown at a particular mating producing a particular chick; and there is the very indeterminate boundary between phases in the chicks. The analysis of this factor must wait until a more objective means of classification has been devised.

TABLE 3

\begin{tabular}{|c|c|c|c|c|}
\hline Mating & $\begin{array}{l}\text { Observed } \\
\text { segregation }\end{array}$ & $\chi^{2}$ & $\begin{array}{l}\text { Degrees of } \\
\text { freedom }\end{array}$ & Probability \\
\hline $\mathrm{P} \times \mathbf{I}$ & $36 \mathrm{P}+45 \mathrm{I}$ & $\mathrm{I} \cdot 0000$ & I & 0.32 \\
\hline$I \times I$ & ${ }_{15} \mathrm{P}+37 \mathrm{I}+8 \mathrm{D}$ & $4 \cdot 9000$ & 2 & 0.099 \\
\hline$I \times D$ & $125 \mathrm{I}+52(\mathrm{P}+\mathrm{D})$ & $30 \cdot 1073$ & I & $<0.001$ \\
\hline
\end{tabular}

Owing to the very homogeneous estimate of " $\lambda$ " which the data reveal, however, and the absence of any other plausible hypothesis, it seems that the one locus theory is the best that can be put forward at the moment. It is rather unfortunate that the recapture of chicks which have started to breed does not seem to throw any light on the problem : except that the one factor theory is not rejected by these data.

\section{EVOLUTIONARY PROBLEMS}

The existence of a cline in the proportion of the different phases has already been mentioned. It is therefore interesting to see whether this is a stationary cline of the type discussed by Fisher (1950) or a moving cline (Fisher, I937). The numbers of the different phases for each year since I95 I at Fair Isle are as shown in table 4. A contingency $\chi^{2}$ for fourteen degrees of freedom gave 7.535 which indicates that there is no reason to suppose any change in the relative proportions of the phases from I $95^{\text {I }}$ to I $95^{8}$.

This result does not necessarily prove that the cline is in this case a stationary one; the breeding life of the Arctic skua appears to be fairly long; and as the colony has increased each year, it seems doubtful that an equilibrium of the type postulated by Fisher can have 
yet been set up. On the other hand, it would seem likely that some of the new birds which have arrived in the colony each year have come from other Orkney and Shetland colonies, and so it is not improbable that the relative proportions of the phases in this part of the cline have in fact remained more or less the same.

It seems possible that this cline may demonstrate another feature of great theoretical interest: this concerns the dominance relations within the cline.

The theory of a cline has been studied by Fisher as already indicated and Haldane (1948). Haldane considered the apparently unrealistic case of complete dominance with a gene at a constant selective advantage on one side of a boundary and at a constant disadvantage on the other. It appears more likely that there is a selective gradient with the gene frequencies maintained in equilibrium by

TABLE 4

\begin{tabular}{|c|c|c|c|c|}
\hline \multirow{2}{*}{ Year } & \multicolumn{3}{|c|}{ Phase } & \multirow{2}{*}{ Total } \\
\hline & Pale & Intermediate & Dark & \\
\hline I95 I & 8 & 22 & 20 & 50 \\
\hline $195^{2}$ & I I & 20 & $2 \mathrm{I}$ & $5^{2}$ \\
\hline 1953 & I 7 & 24 & I 5 & $5^{6}$ \\
\hline I 954 & I 5 & 33 & 20 & 68 \\
\hline I955 & 22 & $3^{8}$ & 28 & 88 \\
\hline 1956 & 26 & 47 & $3^{\mathrm{I}}$ & I 04 \\
\hline 1957 & 27 & 53 & 32 & I 12 \\
\hline $195^{8}$ & 25 & 57 & 39 & I 2 I \\
\hline Total & I $5 \mathrm{I}$ & 294 & 206 & $65 \mathrm{I}$ \\
\hline
\end{tabular}

migration and selection: this is the case that Fisher considered and he also gave the apparatus for fitting. Fisher suggested that true dominance might indicate the very different mechanism of balanced polymorphism. It is clear that the evolution of true dominance can only occur once the population has become isolated from the migration taking place within the cline: the introduction of alien gene complexes must continually break down the modifier balance. There would seem, however, to be the possibility of a cline in dominance with a gene tending to be recessive in areas where it is low in frequency and dominant where it is abundant. If, as in Fisher's theory, there is a selective gradient along the cline, then selection must also be acting on genes modifying the expression and penetrance of the observed character. Thus we can expect not only an equilibrium between migration and selection acting on the factor itself, but also a series of such equilibria determining the frequencies of all the modifiers. Whether this will result in a cline in the dominance relations between the two alleles will depend on the number of modifiers 
and the intensity of the selective gradient. Fisher adopts a standard unit of length such that

$$
a^{3}=4 k / g
$$

where " $k$ " is the coefficient of diffusion, " $g$ " the selective gradient and " $a$ " the distance separating the line on which the gene frequency is 10.04 per cent. from the line of 50 per cent. Since the selective intensity acting on the modifiers will be much less than that acting on the gene itself, it follows that the wave length of the frequency of each individual modifier will be much longer. Thus although there is no theoretical necessity for a cline in dominance to exist, yet the discovery of such a cline would provide very convincing evidence of the power of the evolution of dominance in nature.

That this is a possibility in the Arctic skua is shown by the fact that at Fair Isle the intermediates are very much more like darks than pales; and, indeed, they appear to overlap the darks: pale must therefore show a tendency towards recessiveness. This is as the theory demands, for it must be assumed that in the southern part of the range where pales are the least frequent of the classes there is selection against pale. The proof of this theory must wait upon an examination of the genetics of the phases in colonies where pales are more abundant. A partial confirmation of this idea, however, is indicated in Southern's paper. He mentioned that L. S. V. Venables, who collected data in the Faeroes, noticed there the occurrence of intermediates and was unable to classify birds as either pale or dark in about half a dozen cases. This suggests that pale may start to show a tendency towards dominance in areas not very far north of the Shetlands.

\section{SUMMARY}

I. The three colour phases shown by Arctic skuas are described; breeding data are given; and a possible explanation of the genetic mechanism is put forward.

2. It is suggested, on the basis of observations on the numbers of the different phases made at Fair Isle since I95 I, that the cline in these phases is a stationary one.

3. The theoretical possibility of a cline in dominance relations is discussed and it is noted that the Arctic skua could prove to be an example of this.

Acknowledgment.-One of us (P. O'D.) gratefully acknowledges a Nature Conservancy Research Studentship during the progress of this work.

\section{REFERENCES}

FISHER, R. A. 1937. The wave of advance of advantageous genes. Annals of Eugenics, 8, 355-369.

FISHER, R. A. 1950. Gene frequencies in a cline determined by selection and diffusion. Biometrics, 6, 353-36 $\mathrm{I}$.

HALDANe, J. B. s. 1948. The theory of a cline. 7. Genet., 48, 277-284.

SOUtHERN, H. N. 1943. The two phases of Stercorarius parasiticus L., Ibis, 85, 443-485. williamson, к. 195I. Fair Isle Bird Observatory Bulletin. 